$\mathrm{DE}$

M E D I C I N A

T R O P I C A L

$\mathrm{DE}$

SÃO PAULO

JOURNAL OF THE SÃO PAULO INSTITUTE OF TROPICAL MEDICINE

${ }^{1}$ Instituto Conmemorativo Gorgas de

Estudios de la Salud, Panama

2Universidade de São Paulo, Faculdade de Medicina, Departamento de Patologia, São Paulo, São Paulo, Brazil

${ }^{3}$ Hospital Santo Tomás, Departamento de

Patología, Panama

${ }^{4}$ Universidad de Panamá, Facultad de

Medicina, Panama

${ }^{5}$ Universidad de Panamá, Facultad de Medicina, Centro de Investigación y Diagnóstico de Enfermedades Parasitarias, Panama

Correspondence to: Azael Saldaña Instituto Conmemorativo Gorgas de Estudios de la Salud, Av. Justo Arosemena y calle, 35, 0816-436, Panama

E-mail: asaldana@gorgas.gob.pa

Received: 18 September 2017

Accepted: 17 November 2017

\section{Histopathological characteristics of cutaneous lesions caused by Leishmania Viannia panamensis in Panama}

\author{
Kadir González ${ }^{1,2}$, Rosendo Diaz ${ }^{3}$, Aurea F. Ferreira², Víctor García ${ }^{3}$, Héctor \\ Paz ${ }^{1}$, José E. Calzada ${ }^{1}$, Michelle Ruíz ${ }^{4}$, Márcia Laurenti ${ }^{2}$ Azael Saldaña ${ }^{1,5}$
}

\section{ABSTRACT}

Cutaneous leishmaniasis (CL) is an endemic disease in the Republic of Panama, caused by Leishmania (Viannia) parasites, whose most common clinical manifestation is the presence of ulcerated lesions on the skin. These lesions usually present a chronic inflammatory reaction, sometimes granulomatous, with the presence of lymphocytes, plasma cells and macrophages. This study describes the histopathological characteristics found in the skin lesions of patients with CL caused by Leishmania (V.) panamensis in Panama. We analyzed 49 skin biopsy samples from patients with clinical suspicion of CL, by molecular tests (PCR for subgenus Viannia and HSP-70) and by Hematoxylin-Eosin staining. Samples were characterized at the species level by PCR-HSP-70/RFLP. From the 49 samples studied, 46 (94\%) were positive by PCR and were characterized as Leishmania $(V$. $)$ panamensis. Of these, $48 \%$ were positive by Hematoxylin-Eosin staining with alterations being observed both, in the epidermis ( $85 \%)$ and in the dermis $(100 \%)$ of skin biopsies. The inflammatory infiltrate was characterized according to histopathological patterns: lymphohistiocytic (50\%), lymphoplasmacytic (61\%) and granulomatous (46\%) infiltration, being the combination of these patterns frequently found. The predominant histopathological characteristics observed in CL lesions caused by L. (V.) panamensis in Panama were: an intense inflammatory reaction in the dermis with a combination of lymphohistiocytic, lymphoplasmacytic and granulomatous presentation patterns and the presence of ulcers, acanthosis, exocytosis and spongiosis in the epidermis.

KEYWORDS: Cutaneous leishmaniasis. Leishmania Viannia panamensis. Histopathology. Panama.

\section{INTRODUCTION}

Cutaneous leishmaniasis (CL) is a zoonotic disease caused by parasites of the genus Leishmania, which infects mammalian reservoirs through the bite of an infected vector of the genus Lutzomyia in the New World and Phlebotomus in the Old World ${ }^{1,2}$. Leishmaniasis is among the group of neglected tropical infections, leading to high levels of morbidity mainly among the most vulnerable social groups ${ }^{3,4}$. In Panama, it is considered an emerging health problem with an estimated 1,000-3,000 new cases per year ${ }^{5}$. In 2011, the Pan American Health Organization (PAHO) reported Panama as the country with the highest incidence of CL per 100,000 habitants in the American continent ${ }^{6}$.

CL presents a spectrum of clinical and histopathological manifestations that encompass different morphological states such as a nodule, plaque and ulcer; and which may persist as a chronic lesion or heal with a scar, depending on the infecting parasite species ${ }^{7}$. The lesion may later recur ${ }^{8}$. Commonly, the infection presents 
as cutaneous lesions in exposed areas of the patient, being the skin the main affected organ. Once the parasite invades the skin, after the innate immune response, the defense against infection is the cell-mediated immune response, which actively participates in the formation of granuloma eventually limiting the spread of the infectious agent and, in this way, controlling the infection ${ }^{1}$.

Because the current CL treatment is complicated and is often associated with drugs that have adverse effects, diagnostic confirmation prior to treatment is important. The main diagnostic data are clinical and epidemiological; however, additional laboratory testing is required for definitive diagnosis. Several diagnostic tests are available to confirm the diagnosis: parasitological, immunological, histopathological, immunopathological and molecular ${ }^{9}$. Histopathological techniques are important because they allow observing the parasite and studying the inflammatory infiltrate that is produced during infection by Leishmania parasites ${ }^{9-11}$. The cutaneous lesion of leishmaniasis is characterized by a chronic inflammatory reaction, sometimes granulomatous, with the presence of lymphocytes, plasma cells and macrophages. Leishmania amastigotes are found in the cytoplasm of macrophages as rounded organisms, with a round nucleus, a kinetoplast and surrounded by a clear halo ${ }^{9,11,12}$. Two histological patterns have been reported in patients with active CL lesions. The first one is a non-specific chronic inflammatory reaction with a diffuse infiltrate of lymphocytes, plasma cells, macrophages, granulocytes and cell debris. The second one, a granulomatous reaction that contains histopathological elements found in a chronic inflammatory reaction, but associated with the presence of epithelioid cells and the formation of granulomas, frequently associated with giant cells. Vasculitis, neuritis and necrosis have also been observed. In scarred lesions, dermal fibrosis and perivascular infiltrates can be found ${ }^{13}$. The first reports of CL in Panama were those described by Darling in $1911^{14}$, Herrick in $1911^{15}$, Darling and Connor in $1911^{16}$ and Bates in $1913^{17}$, who considered the lesions clinically identical to the oriental sore. Fox in $1931^{18}$ summarized the clinical and gross features of the disease as seen in Brazil, but did not stress the histological aspects, which were later summarized by Snow et al. in $1948^{19}$. However, there is only one detailed report from 1952 describing the histopathological changes in skin lesions of patients affected by CL in Panamá ${ }^{20}$. The results showed a rather constant and distinctive histological pattern presented in 20 skin ulcer biopsies due to CL. The cardinal findings of epithelial hyperplasia, poor granulation, intense chronic inflammation of the dermal papillae, inflammatory cells located on sweat glands towards the periphery of the lesion, and lack of blood vessel changes, differentiate leishmaniasis from most cutaneous ulcers; however, positive diagnosis still requires the demonstration of the presence of parasites ${ }^{20}$.

Considering that the histopathological characteristics of these lesions, as well as their diagnostic and predictive value have been poorly documented in Panama, this study had the main aim to describe the histopathological findings of cutaneous lesions caused by Leishmania (V.) panamensis in patients from Panama.

\section{MATERIALS AND METHODS}

\section{Study design}

This study aimed to describe the histopathological features of skin biopsies from patients with CL in Panama. Patients with suspected CL were attended at the Tropical Medicine Clinic, Gorgas Memorial Institute of Health Studies, Panama City. This study was carried out from January 2012 to December 2012. All patients were adults, and accepted, freely and voluntarily, to participate in the study through the signing of informed consents. Patients were biopsied and the histopathological and molecular diagnosis of CL was performed. After CL diagnosis, all patients were treated with meglumine antimonate (Glucantime $^{\mathrm{TM}}$ ) in a dose of $20 \mathrm{mg} / \mathrm{kg} /$ body weight, intramuscularly for 20 days, according to the Panamanian guidelines for Leishmaniasis control ${ }^{21}$.

\section{Biopsy collection}

Forty-nine skin biopsy samples from patients with suspected CL attended at the Tropical Medicine Clinic, Gorgas Memorial Institute of Health Studies, were evaluated. Biopsy specimens were taken with a $5-\mathrm{mm}$ Harris punch (Whatman International Ltd), preceded by the application of local anesthesia and asepsis ${ }^{1,22}$.

\section{Molecular characterization}

DNA extraction from the biopsy samples was performed using the Qiagen QIamp ${ }^{\circledR}$ DNA Blood Mini Kit (Qiagen, CA, USA) according to the manufacturer's instructions. Two protocols based on the polymerase chain reaction (PCR) were used: a PCR to identify the subgenus Viannia (LV-B1 primers), which amplifies the kDNA region of the minicircle yielding a $750 \mathrm{pb}^{23}$ fragment; and the Hsp-70 PCR (F25-R1310 primers) that amplifies a region from the Heat Shock Protein 70 gene yielding a product of $1,286 \mathrm{pb}^{24}$. In addition, samples were characterized by PCRHsp-70/RFLP analysis using the enzymes HaeIII and 
BccI to observe the distinct patterns of Leishmania species that have been previously described ${ }^{25,26}$.

\section{Histopathological analysis}

All samples were fixed in $10 \%$ buffered formalin, and processed within a period of not more than $48 \mathrm{~h}$ to dispose of the paraffin tissue block ${ }^{27,28}$, in the Laboratory of Pathology of Santo Tomas Hospital, Panama city. All tissue samples were dehydrated, cleared, embedded in paraffin, cut into 4-5 $\mu \mathrm{m}$ thick sections and stained with Hematoxylin-Eosin (HE) and Giemsa ${ }^{22}$. Lesion sections were characterized microscopically based on the histological alterations found in the epidermis and in the dermis. At the same time, the intensity and distribution of inflammatory reactions in the dermis were evaluated, as well as the presence of different cell types present in the infiltrate, the formation of granuloma and the parasite load, among other morphological aspects. A comparative, semiquantitative histopathological analysis of the HE-stained sections was performed, attributing crosses according to the intensity of the different characterized processes: (-) negative, $(+)$ discrete, $(++)$ moderate and $(+++)$ intense $^{29}$.

\section{RESULTS}

Cutaneous lesions of $49 \mathrm{CL}$-suspected patients were analyzed using molecular and histopathological methods. Of the patients studied, $73 \%$ were male and $27 \%$ female. Most of the patients $(96 \%)$ came from the province of Panama. The age range was 23 to 71 years with an average of 41 years old. Evolution time of lesions varied from 10 to 90 days with an average of 30 days. The number of lesions ranged from 1 to 8 with an average of 2 lesions per patient, mostly located in the upper limbs (60\%). Out of the total samples, 94\% (46/49) were positive by PCR (Viannia, Hsp-70). Positive PCR Hsp-70 samples (78\%, 36/46) were characterized as $L$. $(V$.) panamensis by PCR-RFLP analysis.

Forty-eight percent (22/46) of the samples were positive to amastigotes by microscopic evaluation of histological sections. In patients with CL lesions of 30 days or less (early lesions), 11 were positive and 13 were negative; and in patients with lesions of more than 30 days of infection (late lesions), 11 were positive and 11 were negative. Moreover, the amount of parasites varied between discreet $(+)$ and intense (+++) in the two groups. Amastigote forms were observed in typical histiocyte phagocytic vacuoles, visible in HE staining (Figure 1). The parasite load presented a variable distribution in both, superficial and middle dermis and even deeper in the subcutaneous fat, with occasional signs of endarteritis.

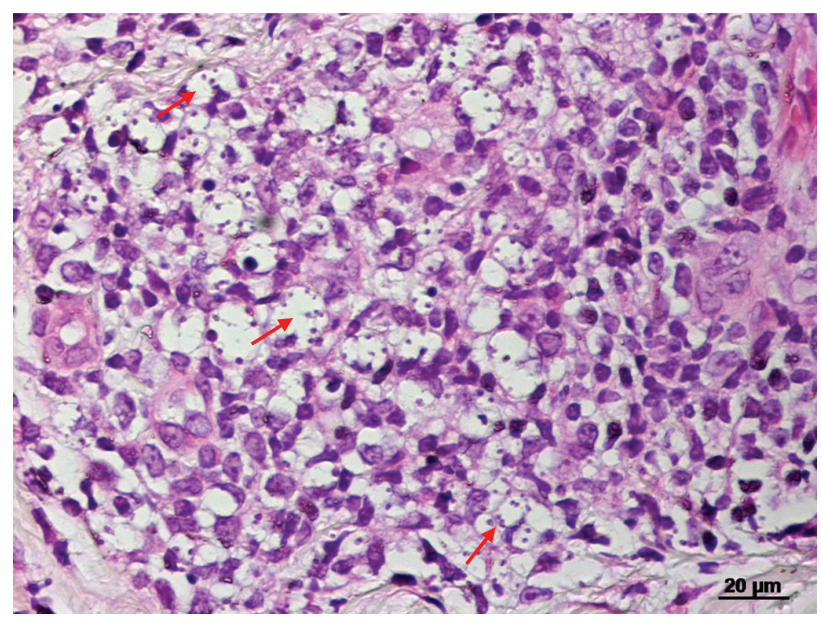

Figure 1 - Amastigotes forms of Leishmania inside macrophages vacuoles in the dermis of patients affected by localized cutaneous leishmaniasis caused by $L$. (V.) panamensis (red arrows). (Hematoxilin-Eosin staining)

The histopathological analysis from the 46 skin biopsies of patients with clinical and laboratory diagnosis of localized CL caused by $L$. (V.) panamensis showed morphological alterations in both, epidermis and dermis. Alterations of the epidermis were observed in 85\% (39/46) of skin biopsies; and were mainly characterized by acanthosis in $41 \%$ (19/46), spongiosis in 39\% (18/46), exocytosis in 35\% (16/46), parakeratosis in $17 \%(8 / 46)$ and pseudoepitheliomatous hyperplasia in $7 \%(3 / 46)$ of the cases (Figure 2). The presence of ulcers in the fundus, border and surface of epidermis was observed in 43\% (20/46) of skin biopsies (Table 1). However, the histopathological alterations in the superficial and deep dermis occurred in 100\% of the cases and were characterized mainly by a lymphoplasmocytic inflammatory infiltrate of variable intensity, with diffuse or focal distribution. The inflammatory infiltrate was intense in 39\% (18/46), moderate in 57\% (26/46) and mild in $4 \%(2 / 46)$ of the cases with diffuse distribution in $37 \%(17 / 46)$ and focal in 63\% (29/46) of the cases. Milder infiltrates were preferentially located in superficial dermis with tendency of perivascular distribution. The inflammatory infiltrate was characterized by predominance of lymphocytes (61\%), followed by histiocytes (22\%) and plasma cells (20\%). Granulomatous outline or well-formed epithelioid granulomas were observed in $46 \%$ (21/46) of the cases, with the presence of multinucleated giant cells in $24 \%(5 / 21)$ and focal necrosis area in $14 \%(3 / 21)$ of these cases. The presence of Leishmania amastigote forms in macrophage cytoplasm was observed in $48 \%(22 / 46)$ of HE-stained histological sections and the parasite load varied from mild, moderate to intense (Table 2). According to different inflammatory cells predominance in the dermal tissue response, it was possible to classify them into three 


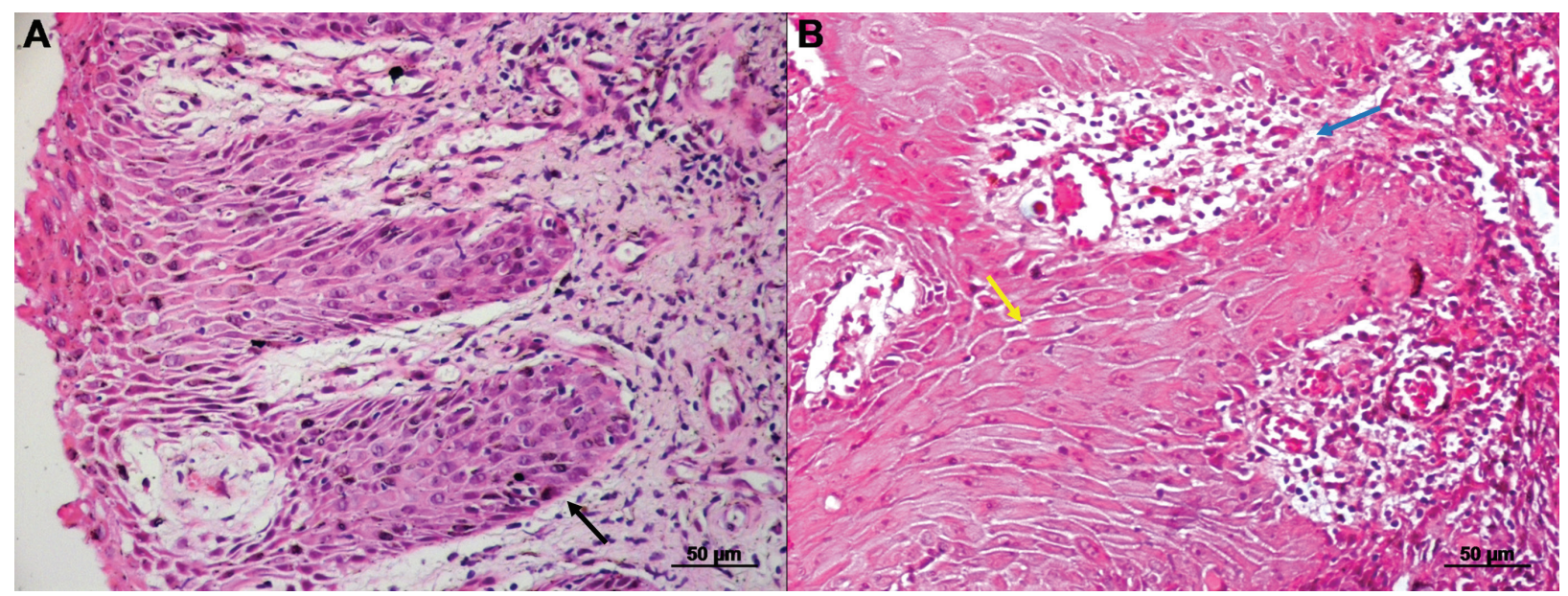

Figure 2 - Paraffin histological section of the skin lesion of a patient affected by localized cutaneous leishmaniasis caused by $L$. (V.) panamensis showing in A) acanthosis (black arrow), and in B) spongiosis (yellow arrow) and lymphohistiocytic exocytosis (blue arrow) (Hematoxilin-Eosin staining)

Table 1 - Histopathological findings observed in the epidermis of patients with cutaneous leishmaniasis caused by Leishmania (V.) panamensis in Panama

\begin{tabular}{lcccccc}
\hline & \multicolumn{7}{c}{ EPIDERMIS } \\
\cline { 2 - 8 } & Ulcer & Acanthosis & Spongiosis & Exocytosis & Paraqueratosis & Hyperplasia \\
\hline Number & $20 / 46$ & $19 / 46$ & $18 / 46$ & $16 / 46$ & $8 / 46$ & $3 / 46$ \\
Percentage (\%) & 43 & 41 & 39 & 35 & 17 & 7 \\
\hline
\end{tabular}

Table 2 - Histopathological findings observed in the dermis of patients with cutaneous leishmaniasis caused by Leishmania ( $V$.) panamensis in Panama

\begin{tabular}{|c|c|c|c|c|c|c|c|c|c|c|}
\hline & \multicolumn{9}{|c|}{ DERMIS - INFLAMMATORY INFILTRATE } & \multirow{3}{*}{ Amastigote } \\
\hline & \multicolumn{3}{|c|}{ INTENSITY } & \multicolumn{2}{|c|}{ DISTRIBUTION } & \multicolumn{4}{|c|}{ CELLULAR TYPE } & \\
\hline & Intense & Moderate & Discrete & Diffuse & Focal & ${ }^{*} \mathrm{PMN}$ & Lymphocyte & Plasma cell & Macrophage & \\
\hline Number & $18 / 46$ & $26 / 46$ & $2 / 46$ & $17 / 46$ & 29/46 & $\begin{array}{c}38 / 46(-) \\
8 / 46(+) \\
0 / 46(++) \\
0 / 46(+++)\end{array}$ & $\begin{array}{c}0 / 46(-) \\
2 / 46(+) \\
15 / 46(++) \\
29 / 46(+++)\end{array}$ & $\begin{array}{c}2 / 46(-) \\
14 / 46(+) \\
20 / 46(++) \\
10 / 46(+++)\end{array}$ & $\begin{array}{c}1 / 46(-) \\
19 / 46(+) \\
15 / 46(++) \\
11 / 46(+++)\end{array}$ & $\begin{array}{c}24 / 46(-) \\
15 / 46(+) \\
2 / 46(++) \\
5 / 46(+++)\end{array}$ \\
\hline $\begin{array}{l}\text { Percentage } \\
(\%)\end{array}$ & 39 & 57 & 4 & 37 & 63 & $\begin{array}{c}83(-) \\
17(+) \\
0(++) \\
0(+++)\end{array}$ & $\begin{array}{c}0(-) \\
4(+) \\
33(++) \\
63(+++)\end{array}$ & $\begin{array}{c}4(-) \\
30(+) \\
44(++) \\
22(+++)\end{array}$ & $\begin{array}{c}2(-) \\
41(+) \\
33(++) \\
24(+++)\end{array}$ & $\begin{array}{c}52(-) \\
33(+) \\
4(++) \\
11(+++)\end{array}$ \\
\hline
\end{tabular}

${ }^{\star}$ PMN: Polimorphonuclear

histopathological patterns: lymphohistiocytic infiltration in 50\% (23/46), lymphoplasmocytic in 61\% (28/46) and granulomatous in $46 \%$ (21/46), being the combination of these patterns frequently found (Figure 3 ).

\section{DISCUSSION}

At least 95\% of leishmaniasis cases reported in Panama correspond to cutaneous lesions of chronic evolution ${ }^{30}$. The clinical diagnosis of these lesions is often complicated, even for physicians experienced in the recognition and treatment of this parasitic disease. On the other hand, it is common to send histological samples of patients with suspected CL lesions to pathology units of reference Panamanian health institutions in which pathologists must have previous experience and academic background. However, studies aimed to characterize CL histopathological findings in Panama are scarce and consequently necessary for the diagnostic and prognostic support of these parasitic infections that are so frequent in this country ${ }^{20}$.

In this work, evaluation by histopathology of 46 patient's lesions with CL previously characterized by 


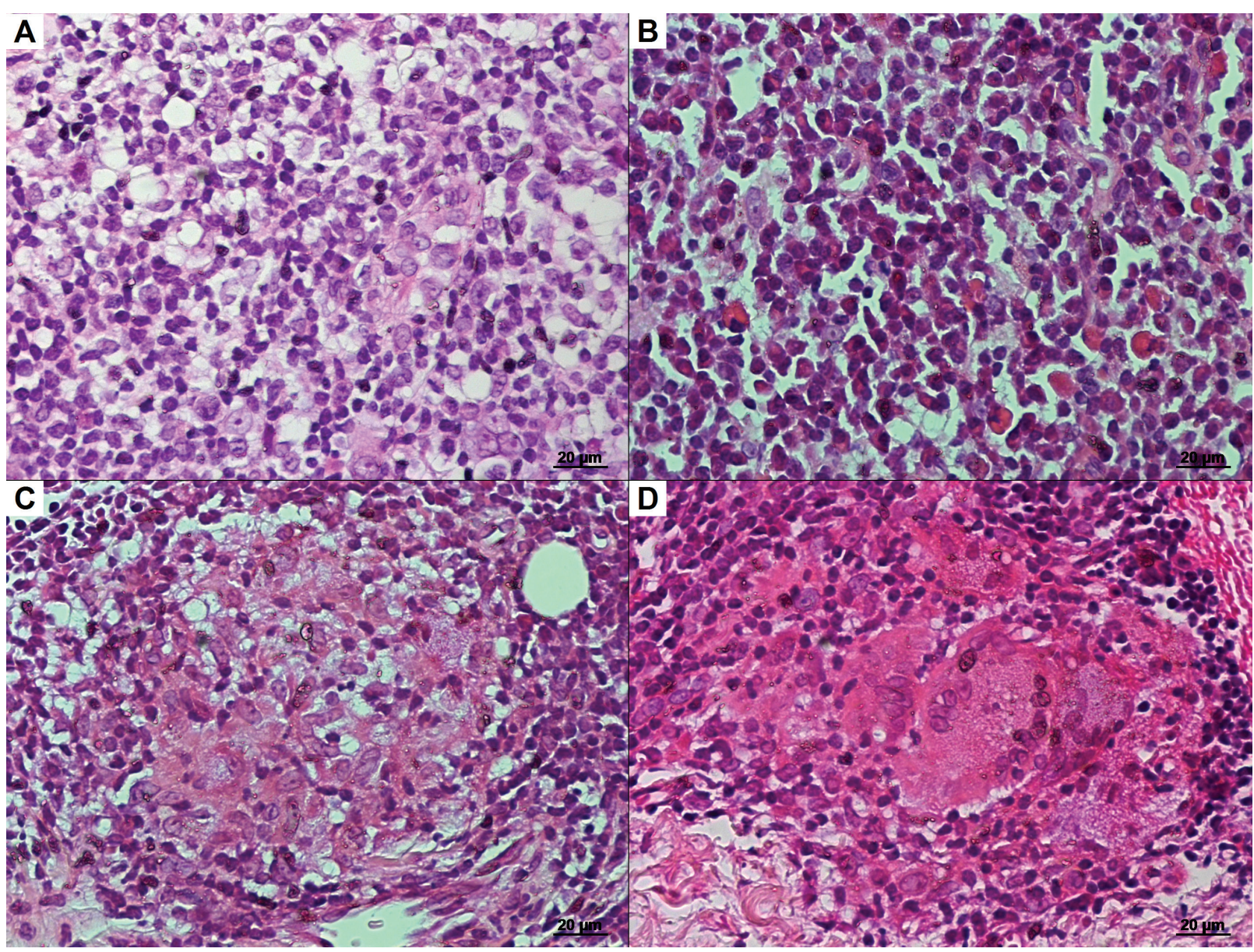

Figure 3 - Inflammatory patterns observed in cutaneous lesions caused by Leishmania (V.) panamensis. A) Intense and diffuse lymphohistiocytic inflammatory pattern; B) Intense lymphoplasmocytic inflammatory pattern; C) Granulomatous inflammatory pattern; D) Presence of multinucleated giant cells observed in the granulomatous reaction (Hematoxilin-Eosin staining)

molecular tests was achieved. However, amastigotes were only detected in $48 \%(22 / 46)$ of biopsies. Amastigotes identified within histiocytes presented a variable distribution along the superficial, middle and deeper layers of dermis. This relatively low diagnostic sensitivity has also been reported in studies with other Leishmania species which are present in South America ${ }^{10,31-33}$. Nevertheless, in these previous reports, it was considered that histopathological tests were important to describe the inflammatory infiltrate associated to leishmaniasis ${ }^{34}$. According to the literature, histopathology is usually the method with the lowest diagnostic sensitivity $(30 \%-60 \%)$ for $\mathrm{CL}^{9,32,35}$. There are several factors that can explain the difficulties of $\mathrm{CL}$ diagnosis by histopathological analysis. One of them occurs in the later stages of the cutaneous infection when granulomas predominate and parasite-filled histiocytes gradually disappear ${ }^{9,36}$. In this regard, it has been reported that parasites are very difficult to find in lesion biopsies with 5-7 months of evolution ${ }^{37,38}$. Thus, we evaluate 23 patients with early lesions (up to 30 days) and 22 with late lesions (31-90 days). However, we did not find statistical differences between the two groups regarding amastigote detection and parasite load. Another situation occurs when there are several opportunistic infections in the same lesion or the same cell type in necrotic areas, making it difficult to observe amastigote forms. The same happens when parasites are free in connective tissues ${ }^{36}$. Occasionally, the histopathological analysis fails to detect amastigotes even in early lesions ${ }^{37}$ which are rarely reported in the epidermis ${ }^{8}$.

Chronic nonspecific and/or granulomatous inflammation are the main histopathological manifestations of cutaneous and mucocutaneous leishmaniasis in the New World ${ }^{9,39}$. The associated infiltration of plasma cells and vascular alterations are suggestive but not diagnostic features of the disease $\mathrm{e}^{20,37,39}$. The specific diagnosis is only possible through the demonstration of parasites in examined tissues ${ }^{29}$. As already mentioned, parasites are generally scarce and difficult to demonstrate in more chronic lesions, thus, immunostaining techniques could be employed to increase the sensitivity of the histopathological diagnosis ${ }^{37,38}$. However, there are studies, using immunostaining techniques, that demonstrated that it is possible to obtain 
higher sensitivities in CL histopathological diagnosis ${ }^{10,33,40}$. In this sense, Sotto et al. ${ }^{39}$ analyzed 40 biopsies of human patients with cutaneous or mucocutaneous leishmaniasis in South America, evidencing the presence of parasites in $20 \%$ of biopsies in histological sections stained by HE, while by indirect immunofluorescence of paraffin-embedded tissues, the positivity increased to $89.28 \%$ and by the immunoperoxidase reaction, it was possible to visualize the parasite in $64.51 \%$ of biopsies.

Morphological analysis of lesions showed a variable parasite load (discrete to intense) and inflammatory infiltrates of variable intensity with diffuse or focal distribution. Inflammatory infiltrates were characterized by lymphocytes predominance, followed by histiocytes and plasma cells. The epidermis showed acanthosis, spongiosis, exocytosis, parakeratosis and pseudoepitheliomatous hyperplasia. In addition, lesions demonstrated the presence of ulcers, focal necrosis area and well-organized granulomas. The presence of well-organized granulomas with multinucleated giant cells is a factor related to the immune system attempt to eliminate parasites ${ }^{41}$. Similar histopathological features have been described in previous studies which analyzed biopsies obtained from patients infected with species from the Viannia subgenus ${ }^{33,34,41-43}$.

In the present study, 63\% (29/46) of the tissue inflammatory response was found to be focal in the tissue, in contrast to data reported by Isaza et al. ${ }^{1}$, showing that inflammatory response was diffuse $(62.5 \%)$ in biopsies of patients coming from endemic areas of the State of Antioquia in Colombia. These patients had CL caused by $L$. $(V$.$) panamensis. In addition, Isaza et al. { }^{1}$ described a predominance of macrophages and lymphocytes in the inflammatory infiltrate in accordance with our study. At the epidermis level, we found the presence of exocytosis in $35 \%$ of the samples. This cellular process was also observed (69.5\%) in the study by Isaza et al. ${ }^{1}$ The presence of the exocytosis phenomenon emphasizes the importance of the epidermis in the immunoregulation of the disease $\mathrm{e}^{44}$.

The histological spectrum of CL has had variations in its classification in different types. For example, Kurban et $a l .{ }^{45}$ and Mansour et al.$^{46}$, suggested two histological patterns in biopsies of patients with CL: the first one corresponding to lesions with less than one year of duration associated with a diffuse infiltrate, and the second one corresponding to lesions of more than one year of duration with granulomatous infiltrate. On the other hand, Venkataram et al. ${ }^{37}$ reported four histological patterns suggestive of CL. Moreover, Magalhães et al. ${ }^{22}$ and Ridley et al. ${ }^{47}$ described up to five histopathological patterns. In the present study, three main histopathological patterns were identified: the first one with a lymphohistiocytic inflammatory response found in 50\% of samples, the second one with a lymphoplasmacytic response, present in $61 \%$ of samples and the third one with a granulomatous response, found in $46 \%$ of samples. It is important to mention that sometimes these patterns appear combined. For example, Azogue ${ }^{48}$ describes a histiolymphoplasmocytic response in $66 \%$ of $\mathrm{CL}$ cases associated with granulomatous reactions and Magalhães et al. ${ }^{24}$ described that $40.9 \%$ of CL cases had characteristic histiolymphoplasmocytic responses with cellular exudative reaction patterns and disorganized granulomatous reactions in $26.1 \%$ of biopsies. In contrast, Isaza et al. ${ }^{1}$ did not find granulomatous infiltrates in his study.

The histopathological and immunological host response to infection caused by parasites of the genus Leishmania, depends largely on the infecting parasite species ${ }^{7,49}$. In this sense, Silveira et al. ${ }^{34}$ described the clinical and immunopathological spectrum of the American CL, caused by different dermotropic species of the parasite responsible for the disease in the New World. While $L$. $(V$.) braziliensis presents a clear tendency to lead to localized cutaneous leishmaniasis (moderate T-cell hypersensitivity response), progressing to mucocutaneous leishmaniasis (prominent Th1 type immune response), $L$. (Leishmania) amazonensis shows an opposite tendency, leading infection to the anergic T-cell hyposensitivity pole, in association with a Th2 type of cellular immune response. The cellular immune response of the host also influences the histopathological aspect of skin lesions. Localized cutaneous leishmaniasis caused by $L$. $(L$.) amazonensis shows a dense inflammatory infiltrate of vacuolated macrophages in the dermis with a large number of amastigote forms, giving to the infiltrate the appearance of a macrophagic granuloma. This morphological aspect of the skin lesion differs from the localized cutaneous leishmaniasis cases caused by $L$. $(V$.) braziliensis and other species of the subgenus Viannia, where there is a predominance of a more modest infiltrate of macrophages with a generally scarce parasite load, however, lymphocytes and plasma cells are more frequent in the presence of wellformed epithelioid granulomas ${ }^{7,34,50}$.

\section{CONCLUSIONS}

In conclusion, the histopathological changes observed in localized CL caused by $L$. (V.) panamensis in Panama were characterized by an intense inflammatory reaction in the dermis with diffuse predominance and lymphohistiocytic, lymphoplasmocytic and granulomatous presentation patterns, as well as the presence of ulcers, acanthosis, exocytosis and spongiosis in the epidermis. However, 
none of them are specific to establish the diagnosis by histopathology. Under the conditions described above, the sensitivity of the histopathological technique in the diagnosis of CL caused by $L$. (V.) panamensis was $48 \%$.

\section{ETHICAL CONSIDERATIONS}

This study was approved by the National Bioethics Committee of Research of the Gorgas Memorial Institute of Health Studies, Panama and by the Ethics Research Committee of the Faculty of Medicine of the University of São Paulo, Brazil, Protocol No 141/13.

\section{ACKNOWLEDGMENTS}

To the following people who helped in a great way with the accomplishment of this work: Salomón Puga, Roberto Rojas, Aracelis Miranda, Thaise Tomokane. Azael Saldaña and José E. Calzada are members of the SNI-SENACYT, Panamá. Marcia Laurenti is a research fellow from National Research Council (CNPq) grant $N^{\circ} 303098 / 2014-7$. This project was carried out with the support of the Sistema Nacional de Investigación (SNI-SENACYT, Panamá) and the São Paulo Research Foundation (FAPESP) grants $\mathrm{N}^{\circ}$ 2014/51404-9 and $N^{\circ}$ 2017/03141-5.

\section{AUTHORS' CONTRIBUTIONS}

Hector Paz helped with patient sampling and care. Victor García performed the histopathological processing of the samples. José Calzada, Marcia Dalastra Laurenti, Michelle Ruíz and Azael Saldaña assisted in drafting the manuscript and in coordinating the study. Rosendo Díaz and Kadir González are, in the same way, the main authors. Both worked on the processing and analysis of the samples. Azael Saldaña is the corresponding author.

\section{CONFLICT OF INTERESTS}

The authors declare no potential conflict of interest.

\section{REFERENCES}

1. Isaza DM, Restrepo M, Restrepo R, Caceres-Dittmar G, Tapia FJ. Immunocytochemical and histopathologic characterization of lesions from patients with localized cutaneous leishmaniasis caused by Leishmania panamensis. Am J Trop Med Hyg. 1996;55:365-9.

2. Grimaldi G Jr, Tesh RB, McMahon-Pratt D. A review of the geographic distribution and epidemiology of leishmaniasis in the New World. Am J Trop Med Hyg. 1989;41:687-725.
3. Mathers CD, Ezzati M, Lopez AD. Measuring the burden of neglected tropical diseases: the global burden of disease framework. PLoS Negl Trop Dis. 2007;1:e114.

4. Bern C, Maguire JH, Alvar J. Complexities of assessing the disease burden attributable to leishmaniasis. PLoS Negl Trop Dis. 2008;2:e313.

5. González K, Calzada JE, Saldaña A, Rigg CA, Alvarado G, Rodríguez-Herrera B, et al. Survey of wild mammal hosts of cutaneous leishmaniasis parasites in Panamá and Costa Rica. Trop Med Health. 2015;43:75-8.

6. Organización Panamericana de la Salud. Organización Mundial de la Salud. Informe final: segunda reunión de gerentes de programas de leishmaniasis de las Américas: Ciudad de Panamá, 8 al 10 de octubre de 2013. Washington: OPS/OMS; 2014.

7. Silveira FT, Lainson R, De Castro Gomes CM, Laurenti MD, Corbett CE. Immunopathogenic competences of Leishmania (V.) braziliensis and L. (L.) amazonensis in American cutaneous leishmaniasis. Parasite Immunol. 2009;31:423-31.

8. Grevelink SA, Lerner EA. Leishmaniasis. J Am Acad Dermatol. 1996;34:257-72.

9. Ríos YJ, Emma YR. Métodos diagnósticos parasitológicos, inmunológicos, histopatológicos y moleculares de Leishmaniasis cutánea. Rev Med Cient. 2010;23:45-60.

10. Xavier SC, de Andrade HM, Monte SJ, Chiarelli IM, Lima WG, Michalick MSM, et al. Comparison of paraffin-embedded skin biopsies from different anatomical regions as sampling methods for detection of Leishmania infection in dogs using histological, immunohistochemical and PCR methods. BMC Vet Res. 2006;2:17.

11. Handler MZ, Patel PA, Kapila R, Al-Qubati Y, Schwartz RA. Cutaneous and mucocutaneous leishmaniasis: differential diagnosis, diagnosis, histopathology, and management. J Am Acad Dermatol. 2015;73:911-26.

12. Machado P, Kanitakis J, Almeida R, Chalon A, Araújo C, Carvalho EM. Evidence of in situ cytotoxicity in American cutaneous leishmaniasis. Eur J Dermatol. 2002:12:449-51.

13. Schubach A, Cuzzi-Maya T, Oliveira AV, Sartori A, de OliveiraNeto MP, Mattos MS, et al. Leishmanial antigens in the diagnosis of active lesions and ancient scars of American tegumentary leishmaniasis patients. Mem Inst Oswaldo Cruz. 2001;96:987-96.

14. Darling ST. Oriental sore in Panama. Arch Intern Med. 1911;7:581-97.

15. Herrick AB. An unusual type of oriental sore. Proc Canal Zone Med Assoc Year. 1911;3:21-5.

16. Darling ST, Connor RC. A case of oriental sore (dermal leishmaniasis) in a native Colombian. JAMA. 1911;56:1257-8.

17. Bates LB, Ancon CZ. Leishmaniasis (oriental sore) of the nasal mucosa. JAMA. 1913;60:898.

18. Fox H. American leishmaniasis: report of cases observed in Brazil. Arch Derm Syphilol. 1931;23:480-502. 
19. Snow JS, Satulsky EM, Kean BH. American cutaneous leishmaniasis: report of 12 cases from Canal Zone. Arch Derm Syphilol. 1948;57:90-101.

20. Thornburgh DB, Johnson CM, Elton NW. The histopathology of cutaneous leishmaniasis in Panama. Trans R Soc Trop Med Hyg. 1952;46:550-4.

21. Panamá. Ministério de Salud. Guía para el abordaje integral de la leishmaniasis en Panamá, 2015. Ciudad de Panamá: Ministério de Salud; 2015.

22. Magalhães AV, Moraes MA, Raick AN, Llanos-Cuentas A, Costa JM, Cuba CC, et al. Histopatologia da leishmaniose tegumentar por Leishmania braziliensis braziliensis. 4. Classificação histopatológica. Rev Inst Med Trop São Paulo. 1986;28:421-30.

23. Vergel C, Walker J, Saravia NG. Amplification of human DNA by primers targeted to Leishmania kinetoplast DNA and post-genome considerations in the detection of parasites by a polymerase chain reaction. Am J Trop Med Hyg. 2005;72:423-9.

24. Garcia L, Kindt A, Bermudez H, Llanos-Cuentas A, De Doncker $\mathrm{S}$, Arevalo J, et al. Culture-independent species typing of neotropical Leishmania for clinical validation of a PCR-based assay targeting heat shock protein 70 genes. J Clin Microbiol. 2004;42:2294-7.

25. Montalvo Alvarez AM, Nodarse JF, Goodridge IM, Fidalgo LM, Marin M, Van Der Auwera G, et al. Differentiation of Leishmania (Viannia) panamensis and Leishmania (V.) guyanensis using BccI for hsp70 PCR-RFLP. Trans R Soc Trop Med Hyg . 2010;104:364-7.

26. Montalvo AM, Fraga J, Monzote L, Montano I, De Doncker S, Dujardin JC, et al. Heat-shock protein 70 PCR-RFLP: a universal simple tool for Leishmania species discrimination in the New and Old World. Parasitology. 2010;137:1159-68.

27. Tresserra F, Martinez Lanao MA, Soler MT. Manejo de las muestras para test inmunohistoquímicos, moleculares y genéticos en el cáncer de mama. Rev Senol Patol Mamar. 2016;29:26-31.

28. Engel KB, Moore HM. Effects of preanalytical variables on the detection of proteins by immunohistochemistry in formalinfixed, paraffin-embedded tissue. Arch Pathol Lab Med. 2011;135:537-43.

29. Martins AL, Barreto JA, Lauris JR, Martins AC. American tegumentary leishmaniasis: correlations among immunological, histopathological and clinical parameters. An Bras Dermatol. 2014;89:52-8.

30. Miranda A, Carrasco R, Paz H, Pascale JM, Samudio F, Saldaña A, et al. Molecular epidemiology of American tegumentary leishmaniasis in Panama. Am J Trop Med Hyg. 2009;81:56571.

31. Ramírez JR, Agudelo S, Muskus C, Alzate JF, Berberich C, Barker $\mathrm{D}$, et al. Diagnosis of cutaneous leishmaniasis in Colombia: the sampling site within lesions influences the sensitivity of parasitologic diagnosis. J Clin Microbiol. 2000;38:3768-73.
32. Quintella LP, Cuzzi T, Madeira MF, Okamoto T, Schubach AO. Immunoperoxidase technique using an anti-Leishmania (L.) chagasi hyperimmune serum in the diagnosis of cultureconfirmed American tegumentary leishmaniasis. Rev Inst Med Trop Sao Paulo. 2009;51:83-6.

33. Alves CF, Alves CF, Figueiredo MM, Souza CC, Machado-Coelho GL, Melo MN, et al. American tegumentary leishmaniasis: effectiveness of an immunohistochemical protocol for the detection of Leishmania in skin. PLoS One. 2013;8:e63343.

34. Silveira FT, Lainson R, Corbett CE. Clinical and immunopathological spectrum of American cutaneous leishmaniasis with special reference to the disease in Amazonian Brazil: a review. Mem Inst Oswaldo Cruz. 2004;99:239-51.

35. Yuil JM, Saldaña A, Calzada J, Arias J, Díaz R, González K. Comparación entre histopatología y PCR, para diagnóstico de leishmaniasis tegumentaria. Dermatol Cosmet Med Quir. 2012;10:13-20.

36. Hofman V, Brousset P, Mougneau E, Marty P, Lamant L, Antoine JC, et al. Immunostaining of visceral leishmaniasis caused by Leishmania infantum using monoclonal antibody (19-11) to the Leishmania homologue of receptors for activated C-kinase. Am J Clin Pathol. 2003;120:567-74.

37. Venkataram M, Moosa M, Devi L. Histopathological spectrum in cutaneous leishmaniasis: a study in Oman. Indian J Dermatol Venereol Leprol. 2001;67:294-8.

38. Saldanha MG, Queiroz A, Machado PR, Carvalho LP, Scott P, Carvalho Filho EM, et al. Characterization of the histopathologic features in patients in the early and late phases of cutaneous leishmaniasis. Am J Trop Med Hyg. 2017;96:645-52.

39. Sotto MN, Yamashiro-Kanashiro EH, da Matta VL, de Brito T. Cutaneous leishmaniasis of the new world: Diagnostic immunopathology and antigen pathways in skin and mucosa. Acta Trop. 1989;46:121-30.

40. Oliveira MA, Pires AS, Bastos RP, Lima GM, Pinto SA, Pereira LI, et al. Leishmania spp. parasite isolation through inoculation of patient biopsy macerates in interferon gamma knockout mice. Rev Inst Med Trop Sao Paulo. 2010;52:83-8.

41. Bittencourt AL, Barral A. Evaluation of the histopathological classifications of American cutaneous and mucocutaneous leishmaniasis. Mem Inst Oswaldo Cruz. 1991;86:51-6.

42. Morgado FN, Schubach A, Rosalino CM, Quintella LP, Santos $\mathrm{G}$, Salgueiro M, et al. Is the in situ inflammatory reaction an important tool to understand the cellular immune response in American tegumentary leishmaniasis. Br J Dermatol. 2008;158:50-8.

43. Castro Gomes CM, Sousa MG, Menezes JP, Batista MC, Lima $\mathrm{AC}$, Belda Jr W, et al. Immunopathological characterization of human cutaneous leishmaniasis lesions caused by Leishmania (Viannia) spp. in Amazonian Brazil. Parasitol Res. 2017;116:1423-31. 
44. Tapia FJ, Cáceres-Dittmar G, Sánchez MA. Inadequate epidermal homing leads to tissue damage in human cutaneous leishmaniasis. Immunol Today. 1994;15:160-5.

45. Kurban AK, Malak JA, Farah FS, Chaglassian HT. Histopathology of cutaneous leishmaniasis. Arch Dermatol. 1966;93:396-401.

46. Mansour L, el-Marhoumy SM, Eid MM, Gawish K. A histopathological study of different clinical forms of cutaneous leishmaniasis. J Egypt Soc Parasitol. 1993;23:591-7.

47. Ridley DS. The pathogenesis of cutaneous leishmaniasis. Trans R Soc Trop Med Hyg. 1979;73:150-60.
48. Esperanza Azogue C. Diagnóstico histopatológico de la leishmaniasis cutánea y cutáneo-mucosa en Bolivia. Mem Inst Oswaldo Cruz. 1983;78:13-20.

49. Mehregan DR, Mehregan AH, Mehregan DA. Histologic diagnosis of cutaneous leishmaniasis. Clin Dermatol. 1999;17:297-304.

50. Silveira FT, Lainson R, Gomes CM, Laurenti MD, Corbett CE. Reviewing the role of the dendritic Langerhans cells in the immunopathogenesis of American cutaneous leishmaniasis. Trans R Soc Trop Med Hyg. 2008;102:1075-80. 